\title{
Effects of Emotional Valence on Hemispheric Asymmetries in Response Inhibition
}

\author{
Sebastian Ocklenburg ${ }^{1, *,+}$ (D), Jutta Peterburs ${ }^{2,+} \mathbb{C}^{\mathbb{D}}$, Janet Mertzen ${ }^{1}$, Judith Schmitz ${ }^{1}$, \\ Onur Güntürkün ${ }^{1}$ and Gina M. Grimshaw ${ }^{3}$ \\ 1 Institute of Cognitive Neuroscience, Biopsychology, Department of Psychology, Ruhr-University Bochum, \\ 44801 Bochum, Germany; janet.mertzen@rub.de (J.M.); judith.schmitz@rub.de (J.S.); \\ Onur.Guentuerkuen@rub.de (O.G.) \\ 2 Institute of Medical Psychology and Systems Neuroscience, University of Münster, 48149 Münster, Germany; \\ jutta.peterburs@uni-muenster.de \\ 3 Cognitive and Affective Neuroscience Lab, School of Psychology, Victoria University of Wellington, \\ 6140 Wellington, New Zealand; Gina.Grimshaw@vuw.ac.nz \\ * Correspondence: sebastian.ocklenburg@rub.de; Tel.: +49-234-32-24323 \\ + These authors contributed equally to the manuscript.
}

Academic Editor: Lesley Rogers

Received: 31 March 2017; Accepted: 26 July 2017; Published: 5 August 2017

\begin{abstract}
Hemispheric asymmetries are a major organizational principle in human emotion processing, but their interaction with prefrontal control processes is not well understood. To this end, we determined whether hemispheric differences in response inhibition depend on the emotional valence of the stimulus being inhibited. Participants completed a lateralised Go/Nogo task, in which Nogo stimuli were neutral or emotional (either positive or negative) images, while Go stimuli were scrambled versions of the same pictures. We recorded the N2 and P3 event-related potential (ERP) components, two common electrophysiological measures of response inhibition processes. Behaviourally, participants were more accurate in withholding responses to emotional than to neutral stimuli. Electrophysiologically, Nogo-P3 responses were greater for emotional than for neutral stimuli, an effect driven primarily by an enhanced response to positive images. Hemispheric asymmetries were also observed, with greater Nogo-P3 following left versus right visual field stimuli. However, the visual field effect did not interact with emotion. We therefore find no evidence that emotion-related asymmetries affect response inhibition processes.
\end{abstract}

Keywords: emotion; lateralisation; hemispheric asymmetry; executive functions; EEG

\section{Introduction}

Hemispheric asymmetries, i.e., functional and structural differences between the left and the right brain hemisphere, affect behaviour and cognition in all vertebrate classes [1-5]. One of the least well understood asymmetric systems is the one that supports emotion processing [6-8]. First reports that the hemispheres might differ in emotional processing are often attributed to Hughlings-Jackson [9], who noted that aphasic patients (with left hemisphere lesions) often had preserved emotional language. Later patient studies showed that left hemisphere lesions are more commonly associated with depressed or catastrophic reactions, whereas right hemisphere lesions are more likely to trigger inappropriate euphoria [10]. These early studies have since been complemented by research using a range of methodologies, including the testing of patients with unilateral lesions [11], asymmetric EEG activity [12,13], visual half-field and dichotic listening techniques [14,15], and functional imaging [16,17], to show that the hemispheres differ in how they process emotional information, and in the emotional responses they generate. 
Two asymmetric systems have been proposed to account for hemispheric differences in emotional processing. The first (described by the "right-hemisphere hypothesis") suggests that the right hemisphere is specialised for the processing of all emotions. The other (described by the "valence" hypothesis) proposes lateralisation as a function of valence, with the left specialised for positive (or approach-related) emotions, and the right for negative (or withdrawal-related) emotions. For decades, researchers have tried to determine which hypothesis better explains emotional asymmetry [18-21]. Rather than pitting these hypotheses against each other, recent research has been based on the premise that both might be correct, and has instead focused on the situations in which emotion-based or valence-based processing might arise [22-24].

There is an emerging consensus that the right hemisphere hypothesis applies largely to emotion perception, regardless of modality, and reflects lateralisation of the right posterior cortex. Such asymmetries may depend largely on the emotional nature of the stimulus, and emerge in a bottom-up fashion. Valence-based processing is more closely tied to emotional experience or expression, and appears to reflect asymmetries in the dorsolateral prefrontal cortex (dlPFC). This asymmetry has been linked to both emotional valence (positive/negative) $[25,26]$ and motivational direction (approach/withdrawal) [27], although valence-related asymmetries are sometimes also reported in perception. Schepman and colleagues have argued that valence effects should emerge when tasks include top-down processing (for example, related to expectancies) that engage frontal emotional processing networks [22,23]. Grimshaw and Carmel [28] have further argued that prefrontal asymmetries in emotional processing may not reflect emotional experience, but the top-down control of emotional information, with the left hemisphere specialised for the inhibition or control of negative information, and the right for inhibition or control of positive emotion. Their rationale is based largely on the fact that prefrontal mechanisms (and particularly those localised to lateral PFC) play a key role in both cognitive and /or attentional control on the one hand, and on emotion regulation on the other [29]. Like Schepman, they argue that valence-based effects are most likely to be observed when tasks involve the use of top-down control mechanisms.

As yet, few experimental studies have directly assessed asymmetries in inhibition or control processes, and so it is unknown whether such control processes show emotional asymmetries, and if so, whether they are in line with either a right hemisphere or valence-based explanation. To address this gap in the literature, we used a lateralized version of the classic Go/Nogo Task in which we manipulated the emotional nature of the stimuli. In this type of task, two categories of stimuli are presented to the subjects: the more frequent Go stimuli to which subjects are asked to respond, e.g., by button press, and the less frequent Nogo stimuli to which participants are asked to withhold responses [30,31]. When Nogo stimuli are rare, participants adopt a prepotent response that must be inhibited when the imperative Nogo signal appears. Poor inhibitory control is indicated by errors of commission on Nogo trials. These behavioural measures are complemented by two neural measures revealed by event-related potentials (ERPs): the Nogo-N2 and the Nogo-P3 [32,33]. These components are assumed to reflect different sub-processes of the response inhibition. The earlier of the two components is the Nogo-N2, a negative component that is thought to reflect either pre-motor inhibition [32] or monitoring of response conflict [34]. The later of the two components is the Nogo-P3, a positive deflection that has been linked to the evaluation of successful inhibition, given that it peaks too late after the response to directly reflect inhibition processes [35-38].

In our version of the task, Go and Nogo stimuli were presented tachistoscopically in the left (LVF) or right visual field (RVF). This ensures that initial visual and emotional processing of the stimulus is lateralized to the contralateral hemisphere [39-42]. To examine emotional processing, we used pictures of emotional and neutral scenes as Nogo stimuli and unidentifiable scrambled versions of the same pictures as Go stimuli. Participants were asked to press a button in response to scrambled stimuli and to refrain from responding whenever intact stimuli were presented. Half of the (intact) Nogo stimuli had a neutral valence, while the other half showed emotional pictures, taken from the International Affective Picture System (IAPS) [43]. We manipulated the valence of the emotional images between 
subjects; for half of the participants, emotional pictures were negative (mutilations), and for the other half positive (erotic scenes). In this task, the emotional content of the Nogo stimuli was not the imperative aspect for the subjects' responses, but instead served merely as a task-irrelevant distraction; that is, participants withheld their response whenever an intact image appeared, regardless of its content. This is an important aspect of the design, as it allows us to assess the effects of the emotional nature of the stimulus to be controlled, independent of any effects of emotion on the generation or inhibition of the response itself (for example, positive and negative stimuli are associated with approach and avoidance responses, respectively).

To our knowledge, no studies have assessed the effects of lateralised emotional stimuli on Go-Nogo task performance. However, a number of studies have manipulated the emotional nature of imperative stimuli in central vision, while still keeping emotion itself incidental to the task [44-49]. The effect of emotion on behavioural measures is mixed across these studies, with some showing more errors on Nogo trials in emotional contexts [50], but most showing no behavioural effects [44,45,49]. However, more consistent findings are reported in the ERP measures. Most studies show no effect of emotion on the Nogo-N2 [44,45,49,51], although some have reported an attenuation of the N2 for emotional relative to neutral stimuli [46,47]. In contrast, emotional stimuli consistently enhance the Nogo-P3 [46,47,51], with effects sometimes greater for positive than for negative stimuli $[44,45]$. This enhanced Nogo-P3 is typically interpreted as a more effortful or less efficient inhibitory control in emotional contexts $[44,45,48]$. Our question concerns the effects of lateralisation of the emotional stimuli on response inhibition processes. Importantly, emotional information can be extracted from peripherally-presented complex scenes, even with very brief stimulus presentations [52,53]. We therefore determined whether emotion affected either behavioural or electrophysiological measures of the response inhibition. Based on the right hemisphere hypothesis, we would expect emotion effects to be stronger for imperative stimuli presented in the LVF. However, because response inhibition depends on top-down control processes, it might be sensitive to emotional valence $[22,23,28]$. If so, we predict stronger effects of negative stimuli in the LVF, and stronger effects of positive stimuli in the RVF.

It is also possible that our experiment will show that response inhibition processes are affected by asymmetries in stimulus processing that are not specific to emotion. Using verbal stimuli, we previously showed that magnitudes of both Nogo-N2 and Nogo-P3 were affected by hemispheric asymmetries in stimulus processing [54]. When lateralised stimuli were presented tachistoscopically, the Nogo-N2 and related delta frequency band power were stronger when response inhibition was applied to stimuli presented in the LVF, implying greater response conflict generated by stimuli presented to the non-dominant hemisphere. A similar, albeit weaker, effect also reached significance for the P3 [54].

\section{Materials and Methods}

\subsection{Subjects}

Forty-two healthy adults (22 women, 20 men) participated in the present study. Subjects were recruited at the Institute of Cognitive Neuroscience, Department of Biopsychology at Ruhr-University Bochum by public advertisement and received course credit or monetary reimbursement $(20 €)$ for participation. The mean age was $24.5 \pm 4.3$ years (range 18 to 34 years). Exclusion criteria were current or past psychiatric or neurological disorders, current psychotropic medication, colour blindness, mixed- or left-handedness, and ages younger than 18 or older than 35 years. Furthermore, subjects were required to be heterosexual due to the nature of the stimulus material (see below). All subjects were right-handed (mean laterality quotient $86.5 \pm 16.1$; range 37.5-100), as assessed with the Edinburgh Handedness Inventory [55], had normal or corrected-to normal vision, and were naïve to the study's intent. 
Written informed consent was obtained from all subjects prior to participation. The study conforms to the Declaration of Helsinki and has received ethical clearance by the Ethics Board of Faculty of Psychology at Ruhr-University Bochum, Germany.

\subsection{Experimental Task}

The task was a tachistoscopic adaptation of a classic Go/Nogo task [30,54] that included emotional and neutral pictures as imperative stimuli. Pictures were taken from the International Affective Picture System (IAPS) [43]. Stimulus presentation and timing was controlled by Presentation software (Neurobehavioural Systems, Inc., Berkeley, CA, USA). Figure 1 provides a schematic illustration of the sequence and time course of stimulus presentation. At the beginning of each trial, a fixation cross was presented in the centre of the screen for $1000 \mathrm{~ms}$. Subsequently an imperative stimulus (emotional or neutral; intact or scrambled picture) was presented in the left (LVF) or right visual field (RVF), with the inner edge of the stimulus located at 3 degrees of visual angle from the fixation cross. Stimuli had a width of 4 degrees of visual angle and a height of 3.5 degrees of visual angle. Stimuli were presented for $185 \mathrm{~ms}$. Stimulus presentation was followed by the fixation cross for $525 \mathrm{~ms}$. Trials were separated by inter-trial intervals jittered between $750 \mathrm{~ms}$ and $950 \mathrm{~ms}$. There was a short break in fixation between the end of the inter-trial interval and the beginning of the next trial in which the fixation cross disappeared and reappeared again.
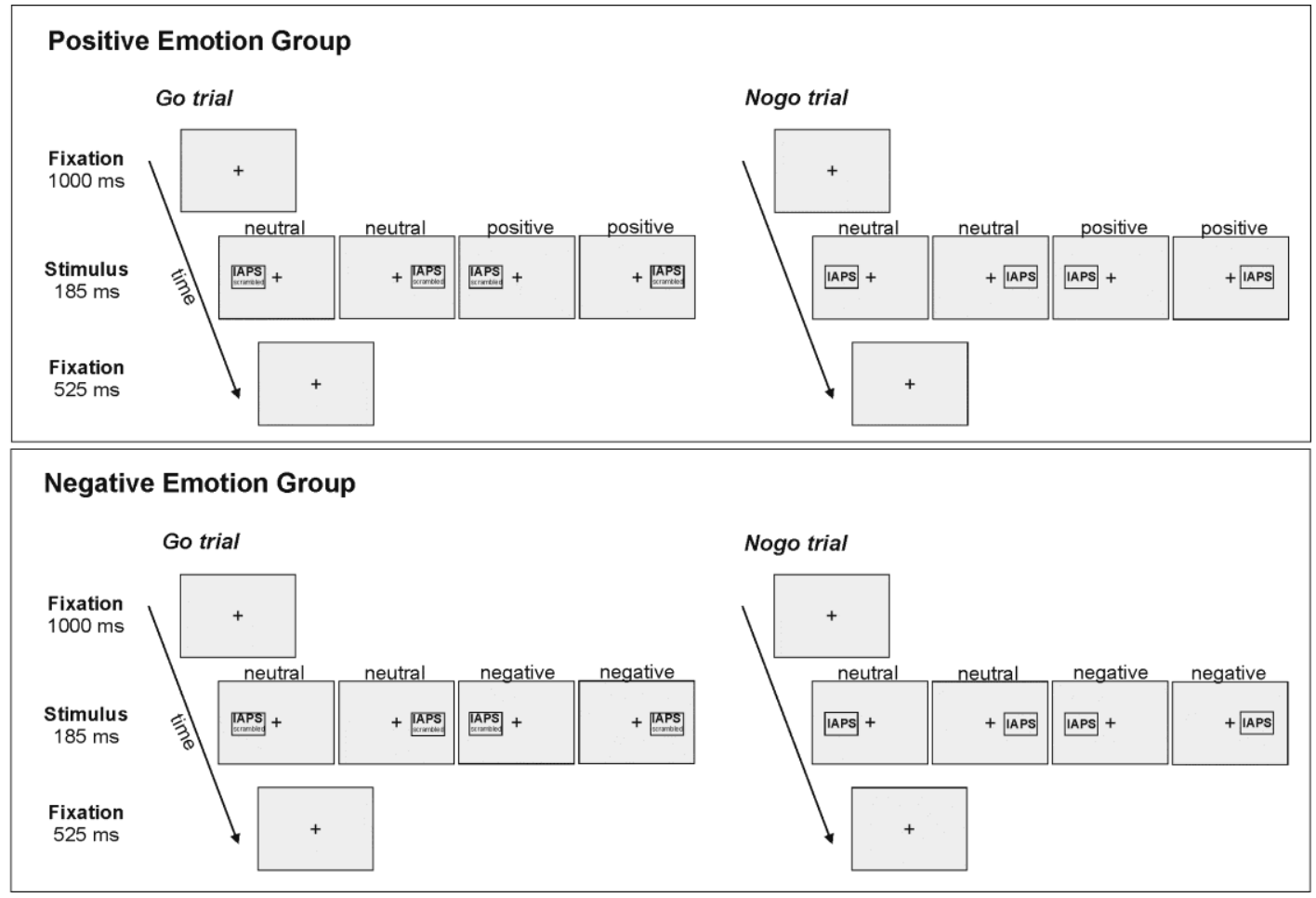

Figure 1. Schematic illustration of the sequence and time course of stimulus presentation. Half of the stimuli for each condition (Go/Nogo) and each valence (positive/neutral or negative/neutral) were presented in the left, the other half in the right visual field. Nogo stimuli were intact IAPS pictures; Go stimuli were scrambled versions of the same IAPS pictures. Trials were separated by inter-trial intervals jittered between $750 \mathrm{~ms}$ and $950 \mathrm{~ms}$.

Stimuli were presented on a 17 inch CRT monitor in a dimly lit room, with subjects seated at a viewing distance of $57 \mathrm{~cm}$. Note that at this viewing distance $1 \mathrm{~cm}$ on the screen equals $1^{\circ}$ of visual angle. Head position was stabilized with a chin rest. Subjects were instructed to keep their gaze on the central fixation cross throughout the entire task, and to press the arrow up key on a key board 
as fast and as accurately as possible whenever a Go stimulus was presented. Participants responded with their right hand on all trials. Only the right hand was used to respond in order to maximize trial numbers in critical conditions. Although contralateral movement-related potentials can arise prior to the imperative stimulus and potentially affect nogo-ERPs, these do not interact with stimulus lateralization, and should therefore have equivalent effects on left and right visual field stimuli $[56,57]$. Furthermore, subjects had to withhold their response whenever a Nogo stimulus was presented. Nogo stimuli were intact (i.e., non-scrambled) emotional or neutral pictures, while Go stimuli were scrambled images of the same emotional or neutral pictures (see Figure 1). For half of the subjects, emotional pictures had a negative valence (negative emotion group). There were 12 images in each category. Negative emotional pictures depicted bodily mutilation, injury, or dead bodies. For the other half of the participants, emotional pictures had a positive valence and depicted erotic (heterosexual) couples (positive emotions group). Neutral images all depicted people engaged in common activities. Comparison of normative ratings [8] revealed that positive images were rated as more pleasant and more arousing than neutral images, and negative images were rated as more unpleasant and more arousing than neutral images (all $p<0.001$ ). Positive and negative images did not differ in arousal $(p=0.13)$. The same picture sets were used for male and female participants, as men and women rate these images similarly. There were 12 female and 10 male participants in the negative emotion group and 10 female and 10 male participants in the positive emotions group. There were no significant differences in gender composition between the two groups $(p=0.77)$.

In total, the task comprised 672 trials, with $29 \%$ (192) Nogo and $71 \%$ (480) Go trials. For each trial type (Go/Nogo), half of the stimuli were emotional (Go: 240; Nogo: 96) and half were neutral, and of those, half were presented in the LVF (Go: 120; Nogo: 48) and half in the RVF. Note, however, that because Go stimuli were scrambled images, they were emotional only in that they were derived from emotional images; they had no emotional meaning of their own. Stimulus presentation was randomized. Task completion took approximately 16 minutes. Accuracy (percentages of correct responses), false alarms (that is, responses on Nogo trials), misses (that is, non-responses on Go trials), and mean response times (RTs) for correct responses were assessed.

\subsection{Electrophysiological Recordings}

EEG was recorded from 64 channels using an actiCAP electrode system with Ag-AgCL electrodes and a standard BrainAmp amplifier, and the corresponding recording BrainVision Recorder software (Brain Products, Gilching, Germany) at a sampling rate of $1000 \mathrm{~Hz}$. Electrodes were arranged according to the International 10-20 system (FCz, FP1, FP2, F7, F3, F4, F8, FC5, FC1, FC2, FC6, T7, C3, Cz, C4, T8, TP9, CP5, CP1, CP2, CP6, TP10, P7, P3, Pz, P4, P8, PO9, O1, Oz, O2, PO10, AF7, AF3, AF4, AF8, F5, F1, F2, F6, FT9, FT7, FC3, FC4, FT8, FT10, C5, C1, C2, C6, TP7, CP3, CPz, CP4, TP8, P5, P1, P2, P6, PO7, $\mathrm{PO}, \mathrm{POz}, \mathrm{PO} 4, \mathrm{PO} 8)$. Electrode $\mathrm{FC} z$ was used as a primary reference. Impedances were kept below $10 \mathrm{k} \Omega$, mostly ranging from 5 to $10 \mathrm{k} \Omega$. Initially, 44 subjects were tested, but in two subjects ( 1 male, 1 female), not enough electrodes could be recorded throughout the task due to technical problems. Data from these subjects were excluded from all analyses, rendering a sample of $\mathrm{N}=42$ for the study, as described above.

EEG data were processed off-line using BrainVision Analyzer 2 (Brain Products, Gilching, Germany). Raw data were first down-sampled to $500 \mathrm{~Hz}$ and filtered with $0.5 \mathrm{~Hz}$ low cutoff and $20 \mathrm{~Hz}$ high cutoff ( $48 \mathrm{~dB} / \mathrm{oct})$. The filtered data were visually inspected and all trials containing gross technical artefacts were rejected. Horizontal and vertical eye movements as well as pulse artefacts were then corrected using infomax independent component analysis (ICA), which was applied to the unepoched data. Epoched data were subjected to automatic artefact rejection applying the following rejection criteria: maximum voltage steps of more than $50 \mu \mathrm{V} / \mathrm{ms}$, maximum value differences of $200 \mu \mathrm{V}$ in $200 \mathrm{~ms}$ intervals, or activity below $0.1 \mu \mathrm{V}$. The overall number of trials rejected by this procedure was below $5 \%$ of all trials for each condition and channel. 
Data analyses (peak and latency quantification) were performed after the calculation of current source density (CSD) of the signal in order to ensure reference-free evaluation [54]. CSD transformation replaces the potential at each electrode with the CSD, thereby eliminating the reference potential. The algorithm applies the spherical Laplace operator to the scalp distribution of the potential. Since this distribution is only known for electrodes that were actually used, spherical spline interpolation is applied to calculate a continuous potential distribution [58].

Data were segmented into $1200 \mathrm{~ms}$ epochs starting $200 \mathrm{~ms}$ before and ending $1000 \mathrm{~ms}$ after onset of Go or Nogo stimuli, respectively. Baseline correction was applied based on the $200 \mathrm{~ms}$ directly preceding the stimulus onset. Segments were averaged according to condition (Go/Nogo), emotionality (emotional/neutral), and side (LVF/RVF). Note that only trials with a correct Go or Nogo response were included. Electrodes used for amplitude and latency quantification were chosen based on the typical scalp topographies for the N2 and P3, as well as on careful visual inspection of grand-average ERPs in the present data set. N2 amplitude and latency were measured based on the maximum negative peak occurring in a time window from 190 to $390 \mathrm{~ms}$ after stimulus onset at electrode FCz. P3 amplitude and latency were measured based on the maximum positive peak occurring in a time window from 300 to $600 \mathrm{~ms}$ after stimulus onset at electrode Pz.

\subsection{Statistical Analysis}

Statistical analyses were performed using IBM SPSS 23 software (IBM Corporation, Armonk, New York, USA). With regard to behavioural performance and accuracy (percentage of correct responses, that is, button presses in the Go condition, and non-responses in the Nogo condition); RTs for correct responses in the Go condition were also analyzed. The significance level was set to $p<0.05$. Effect sizes are provided as the proportion of variance accounted for (partial $\eta^{2}$ ). Mean amplitudes are provided together with the standard error of the mean (SEM as measure of variability).

\section{Results}

\subsection{Behavioural Data}

Overall, participants were significantly more accurate when responding to Go stimuli $(98.10 \%)$ as compared to when withholding their responses to Nogo stimuli $(87.75 \%)\left(t_{(41)}=8.39 ; p<0.001\right)$. Subsequent analyses were carried out only for Nogo trials (see Figure 2), as the factor emotionality could only be interpreted for these trials because stimuli were scrambled on Go trials. Also, as indicated by very high accuracy on Go trials ( $>98 \%)$, there was possibly a ceiling effect in the Go condition.

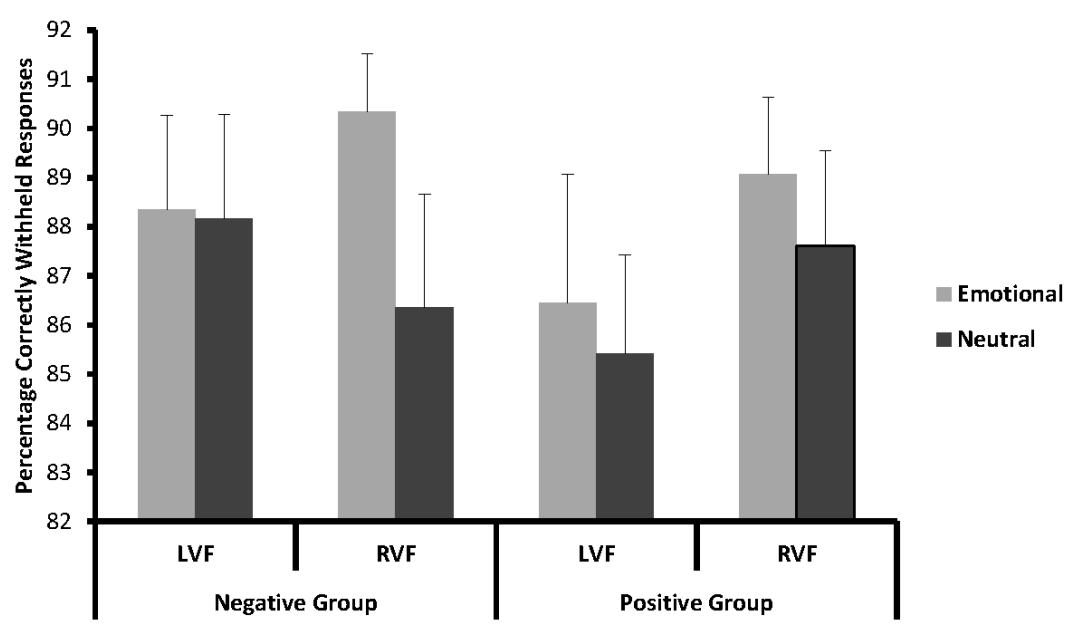

Figure 2. Mean percentage of correctly withheld responses in the Nogo condition for emotional and neutral stimuli in left (LVF) and right (RVF) visual field in the positive and negative emotion groups. 
Accuracy data for the Nogo condition was analysed with a $2 \times 2 \times 2$ repeated measures ANOVA with the within-subjects factors side (LVF/RVF) and emotionality (emotional/neutral), and the between-subjects factor valence (positive/negative). Here, the main effect of emotionality showed a strong trend towards significance $\left(\mathrm{F}_{(1,40)}=3.89 ; p=0.056\right.$; partial $\left.\eta^{2}=0.09\right)$, indicating that participants were more accurate in withholding their responses to emotional $(88.55 \%)$, as compared to neutral, pictures $(86.89 \%)$. All other effects failed to reach significance (all $p>0.13$ ).

\subsection{EEG Data}

\subsubsection{N2}

N2 Amplitude

For N2 amplitude (see Figure 3), analysis revealed a more negative N2 in the Nogo $(-13.82 \mu \mathrm{V} \pm 1.28)$ compared to the Go condition $(-9.25 \mu \mathrm{V} \pm 0.30)$, as was to be expected for a Go/Nogo task $\left(\mathrm{t}_{(41)}=4.47\right.$; $p<0.001$ ). Subsequent analyses of emotion effects were carried out within the Nogo trials. N2 amplitudes in the Nogo condition were analysed with a $2 \times 2 \times 2$ repeated measures ANOVA with the within-subjects factors side (LVF/RVF) and emotionality (emotional/neutral), and the between-subjects factor valence (positive/negative). In this analysis, all effects failed to reach significance (all $p>0.20$ ).

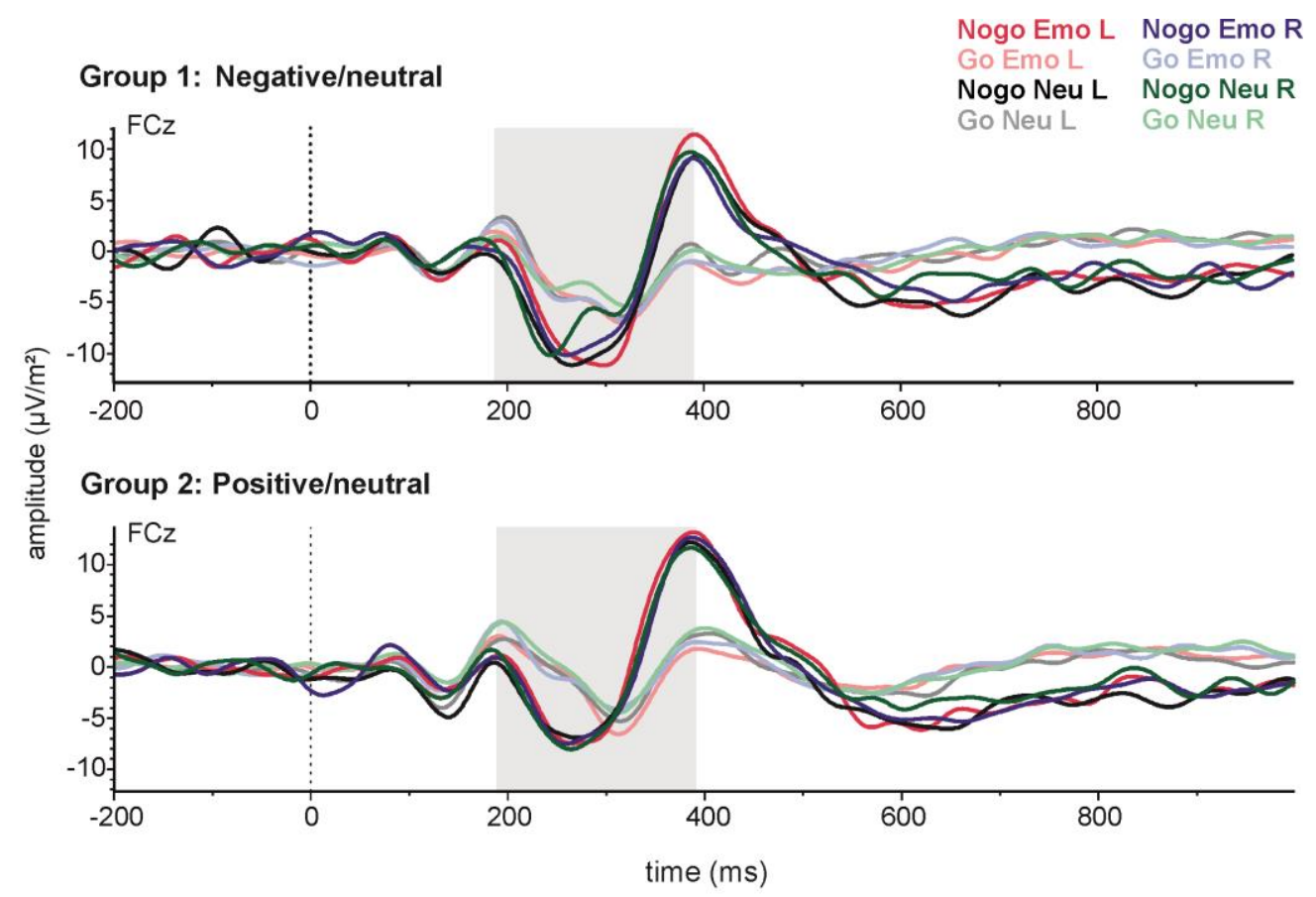

Figure 3. Stimulus-locked grand-average event-related potentials (ERPs) for emotional and neutral Go and Nogo stimuli presented on the left (L) or right (R) side at electrode FCz. The upper panel shows data from the negative emotion group and the lower panel data from the positive emotion group.

\section{N2 Latency}

With regard to latency, the N2 emerged earlier in the Nogo (291.29 ms \pm 5.12$)$ than in the Go condition $(297.28 \mathrm{~ms} \pm 5.84)\left(\mathrm{t}_{(41)}=3.44 ; p<0.01\right)$. Subsequent analyses of emotion effects were carried out within the Nogo trials. N2 latencies in the Nogo condition were analysed with a $2 \times 2 \times 2$ repeated measures ANOVA with the within-subjects factors side (LVF/RVF), and emotionality (emotional/neutral) and the between-subjects factor valence (positive/negative). In this analysis, all effects failed to reach significance (all $p>0.18$ ). 


\subsubsection{P3}

\section{P3 Amplitude}

For P3 amplitude (see Figure 4), greater amplitudes were observed in the Go $(17.27 \mu \mathrm{V} \pm 1.64)$ as compared to the Nogo condition $(12.43 \mu \mathrm{V} \pm 1.60)\left(\mathrm{t}_{(41)}=-5.01 ; p<0.001\right)$. Subsequent analyses were carried out only for Nogo trials, to evaluate effects of emotion. P3 amplitudes in the Nogo condition were analysed with a $2 \times 2 \times 2$ repeated measures ANOVA with the within-subjects factors side (LVF/RVF) and emotionality (emotional/neutral), and the between-subjects factor valence (positive/negative). Here, the main side effect reached significance $\left(\mathrm{F}_{(1,40)}=4.12 ; p<0.05\right.$; partial $\left.\eta^{2}=0.09\right)$, indicating a more positive P3 after stimulus presentation in the LVF (13.31 \pm 1.55$)$ as compared to the RVF $(11.71 \pm 1.53)$. Moreover, the main effect of emotionality $\left(\mathrm{F}_{(1,40)}=16.32 ; p<0.001\right.$; partial $\left.\eta^{2}=0.29\right)$ reached significance, indicating that emotional stimuli lead to a higher P3 (14.01 \pm 1.65$)$ than neutral stimuli $(11.01 \pm 1.41)$. This effect of emotionality on P3 amplitude was modulated by stimulus valence, as indicated by a significant valence $\times$ emotionality interaction $\left(\mathrm{F}_{(1,40)}=11.28\right.$; $p<0.01$; partial $\eta^{2}=0.22$ ). Post-hoc tests revealed no difference between emotional and neutral stimuli in the group of subjects who saw negative emotional images $(p=0.65)$. However, for those who saw positive emotional images, P3 amplitude was greater for emotional stimuli (16.86 \pm 2.39$)$ than for neutral stimuli $(11.37 \pm 2.07)(p<0.001)$. Importantly for our hypotheses, the effects of side and emotion did not interact.

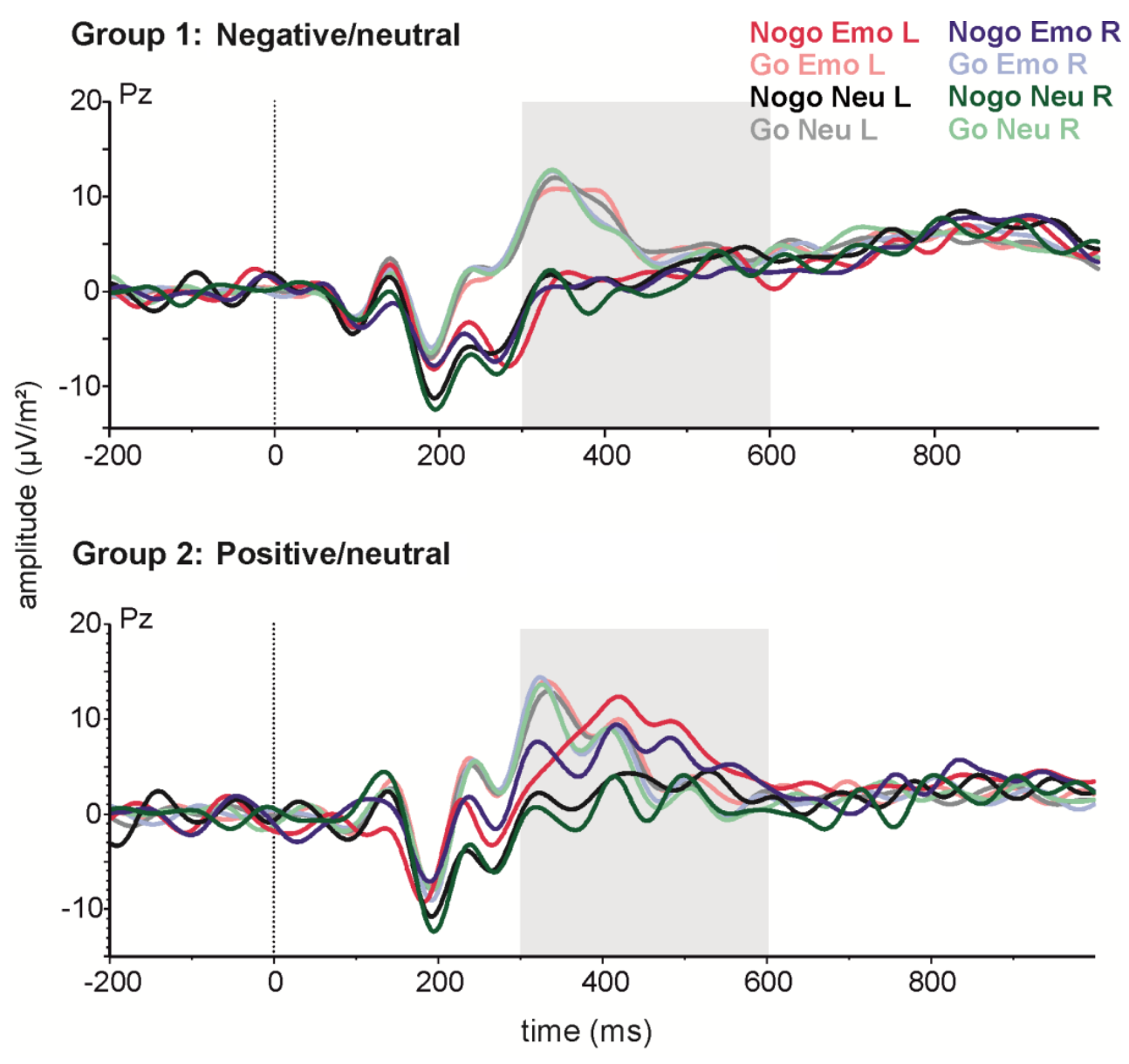

Figure 4. Stimulus-locked grand-average ERPs for emotional and neutral Go and Nogo stimuli presented on the left $(\mathbf{L})$ or right $(\mathbf{R})$ side at electrode Pz. The upper panel shows data from the negative emotion group and the lower panel data from the positive emotions group. 


\section{P3 Latency}

For latency, the P3 emerged earlier in the Go (372.53 ms \pm 9.00$)$ as compared to the Nogo condition $(404.61 \mathrm{~ms} \pm 8.41)\left(\mathrm{t}_{(41)}=-2.84 ; p<0.01\right)$. Subsequent analyses were carried out only for Nogo trials, to evaluate emotion-related effects. P3 latencies in the Nogo condition were analysed with a $2 \times 2 \times 2$ repeated measures ANOVA with the within-subjects factors side (LVF/RVF) and emotionality (emotional/neutral), and the between-subjects factor valence (positive/negative). In this analysis, all effects failed to reach significance (all $p>0.22$ ).

\section{Discussion}

Functional hemispheric asymmetries are one of the core organizational principles underlying many cognitive functions in the human brain, including emotion processing [6-8], but their interaction with prefrontal functions, e.g., executive control, is not well understood. The present study was designed to elucidate the neurophysiological basis of this relationship by recording N2 and P3 ERP components during a divided visual field Go/Nogo task with scrambled (Go) or intact (Nogo) pictures with emotional or neutral content that was incidental to the task. Based on right-hemisphere dominance for emotional processing, we would expect emotion effects to be stronger for imperative stimuli presented in the left visual field than in the right. Alternatively, valence-based models lead to the prediction of stronger effects of negative stimuli in the left visual field, and stronger effects of positive stimuli in the right visual field.

We observed expected differences between Go and Nogo trials in the accuracy data, indicating that our task effectively elicited response conflict and response inhibition [30,32]. Additionally, accuracy on both Go and Nogo trials was high ( $98 \%$ and $88 \%$, respectively), showing that participants were able to distinguish intact from scrambled images even though they were presented only briefly in the periphery. High accuracy also meant that sufficient trials were available for analysis of N2 and P3 responses.

We observed effects of emotion that are broadly consistent with those reported in other studies that have manipulated the emotion of imperative stimuli in Go/Nogo tasks. Behaviourally, emotional stimuli were associated with marginally better performance on Nogo trials, consistent with a "freezing" effect of emotion, perhaps driven by attentional prioritisation of emotional stimulus processing [50]. Turning to the ERP measures, we found no effect of emotion on the Nogo-N2, consistent with other studies $[44,45]$. Collectively, these studies suggest that conflict monitoring processes are not sensitive to emotion. Also consistent with other studies, we observed that Nogo-P3 was enhanced in the presence of positive emotional stimuli [44,45]. The most common interpretation of emotional potentiation of the P3 is that sustained attentional engagement with positive emotional stimuli affects the execution or evaluation of inhibitory processing.

Emotion effects were observed even though stimuli were only briefly presented in peripheral locations, meaning that our experimental paradigm should be sensitive to hemispheric differences in emotional processing if they exist. Nonetheless, neither emotionality nor valence interacted with the visual field on any measure. Our findings therefore do not support either a right hemisphere or valence-based interpretation of emotional processing in the context of response inhibition. This complete lack of asymmetry in emotional processing was unexpected, given robust findings of emotional asymmetry on perceptual processing [6-8]. It is possible that asymmetries were not observed because emotion was incidental to the task, which required participants only to distinguish intact from scrambled stimuli. Many studies that have produced evidence for emotional asymmetries use explicit emotional identification or judgments [6-8], or involve tasks in which emotion is relevant to response [53]. We purposefully made emotion itself task-irrelevant so that we could observe the effects of emotion on control processes independent of any effects on motor execution (e.g., approach and avoidance tendencies that might have been activated by positive and negative stimuli, respectively) [7]. Further studies on the task dimensions that influence emotional asymmetries would be necessary to evaluate this hypothesis. 
Although emotion did not interact with visual field, hemispheric differences were still observed, in that the Nogo-P3 was enhanced for the left visual field relative to right visual field stimuli. This finding is partially consistent with our previous study in which both Nogo-N2 and Nogo-P3 were enhanced for verbal stimuli presented in the left visual field [54]. The fact that similar effects have been observed for both verbal and pictorial stimuli suggests that this effect might not be stimulus-specific, and might instead reflect asymmetry in the application of inhibitory control more broadly. Notably, response inhibition mechanisms have been localised to the right hemisphere [59], and specifically to right inferofrontal cortex [60,61].

The use of lateralised stimuli in Go/Nogo task (especially with ERP measures) is not common in the literature, and further studies are needed using a broader range of stimulus modalities before drawing strong conclusions about how hemispheric asymmetries in stimulus processing affect response inhibition processes. For example, in order to render findings on emotional lateralisation in inhibition-related ERPs more comparable to those found for verbal stimuli [54], it would be an interesting follow-up study to use the emotional content of the stimuli not as a distracting task-irrelevant feature but as the Go/Nogo indicator. Here, emotional stimuli with reduced stimulus complexity should be used. While IAPS pictures are widely used and thus constitute a well-validated stimulus set in emotion processing research, they typically are presented for longer intervals than in the present tachistoscopic experiment when participants must make judgments of valence based on stimulus content. This brief presentation may lead to reduced accuracy when using them as Go/Nogo stimuli. Less complex emotional stimuli, e.g., emotional faces, might be better suited for such tasks (see [62] for a tachistoscopic EEG study that successfully used emotional faces as imperative stimuli). Moreover, in the present study, although it was task-irrelevant, emotion was a stimulus property of the Go/Nogo stimuli. To further disentangle stimulus- and distractor-related effects, it would be informative to use a paradigm with central presentation of non-verbal Go/Nogo stimuli without emotional content (e.g., red and green coloured squares). The distractors (IAPS pictures or emotional faces) would then be presented in the LVF or RVF. By comparing distractor trials to trials without distractors, a more fine-tuned assessment of the effects of left- or right-hemispheric stimulus processing on prefrontal inhibition processes would be possible. Moreover, we used a between-subjects design in the present study, with one group of subjects tested with positive and neutral stimuli and the other group with negative and neutral stimuli. A within-subjects design in which each participant is tested in both conditions would have greater statistical power and should be used in future studies addressing ERP-correlates of emotional lateralization. Additionally, the Go/Nogo task is only one of several paradigms that allow investigation of prefrontally mediated inhibition processes. Other paradigms targeting prefrontal functions that involve inhibition, e.g., the stop-signal task [63], stop-change task [64], or the task-switching paradigm [65] could yield further evidence for a relationship between emotional lateralisation and prefrontal inhibition.

\section{Conclusions}

Emotional asymmetries are commonly observed in perception and in emotional expression and experience. We manipulated the emotional nature of the Nogo stimulus in order to distinguish between right hemisphere and valence-based explanations of emotional asymmetry. P3 amplitudes were enhanced when stimuli were presented in the left visual field, suggesting that evaluative processes involved in response inhibition are sensitive to hemispheric differences in stimulus processing. P3 amplitudes were also potentiated by positive images, showing that the evaluative processes reflected by the P3 are sensitive to emotional content. However, contrary to both right-hemisphere and valence models, we found no evidence that emotional effects depended on the hemisphere to which those stimuli were presented. 
Acknowledgments: This work was partially supported by the G.A. Lienert Foundation with a research stipend awarded to Jutta Peterburs. It was also partially supported by a travel grant from the Global Young Faculty to Sebastian Ocklenburg and by grant VUW1307 from the Royal Society of New Zealand Marsden fund to Gina M. Grimshaw.

Author Contributions: Sebastian Ocklenburg, Jutta Peterburs, Onur Güntürkün and Gina M. Grimshaw conceived and designed the experiments; Janet Mertzen and Judith Schmitz performed the experiments; Janet Mertzen and Sebastian Ocklenburg analysed the data; Onur Güntürkün contributed reagents/materials/analysis tools; Sebastian Ocklenburg, Jutta Peterburs, Onur Güntürkün and Gina M. Grimshaw wrote the manuscript.

Conflicts of Interest: The authors declare no conflict of interest. The founding sponsors had no role in the design of the study; in the collection, analyses, or interpretation of data; in the writing of the manuscript, and in the decision to publish the results.

\section{References}

1. Rogers, L.J. Asymmetry of brain and behavior in animals: Its development, function, and human relevance. Genesis 2014, 52, 555-571. [CrossRef] [PubMed]

2. Rogers, L.J. Development and function of lateralization in the avian brain. Brain Res. Bull. 2008, 76, $235-244$. [CrossRef] [PubMed]

3. Vallortigara, G.; Rogers, L.J. Survival with an asymmetrical brain: Advantages and disadvantages of cerebral lateralization. Behav. Brain Sci. 2005, 28, 575-589. [CrossRef] [PubMed]

4. Ocklenburg, S.; Ströckens, F.; Güntürkün, O. Lateralisation of conspecific vocalisation in non-human vertebrates. Laterality 2013, 18, 1-31. [CrossRef] [PubMed]

5. Ströckens, F.; Güntürkün, O.; Ocklenburg, S. Limb preferences in non-human vertebrates. Laterality 2013, 18, 536-575. [CrossRef] [PubMed]

6. Davidson, R.J. Anterior cerebral asymmetry and the nature of emotion. Brain Cogn. 1992, 20, 125-151. [CrossRef]

7. Onal-Hartmann, C.; Pauli, P.; Ocklenburg, S.; Güntürkün, O. The motor side of emotions: Investigating the relationship between hemispheres, motor reactions and emotional stimuli. Psychol. Res. 2012, 76, 311-316. [CrossRef] [PubMed]

8. Thompson, J.K. Right brain, left brain; left face, right face: Hemisphericity and the expression of facial emotion. Cortex 1985, 21, 281-299. [CrossRef]

9. Hughlings-Jacckson, J. On affections of speech from disease of the brain. Brain 1878, 1, 304-330. [CrossRef]

10. Gainotti, G. Emotional behavior and hemispheric side of the lesion. Cortex 1972, 8, 41-55. [CrossRef]

11. Borod, J.C.; Cicero, B.A.; Obler, L.K.; Welkowitz, J.; Erhan, H.M.; Santschi, C.; Grunwald, I.S.; Agosti, R.M.; Whalen, J.R. Right hemisphere emotional perception: Evidence across multiple channels. Neuropsychology 1998, 12, 446-458. [CrossRef] [PubMed]

12. Coan, J.A.; Allen, J.J.B. Frontal EEG asymmetry as a moderator and mediator of emotion. Biol. Psychol. 2004, 67, 7-49. [CrossRef] [PubMed]

13. Harmon-Jones, E.; Gable, P.A. On the role of asymmetric frontal cortical activity in approach and withdrawal motivation: An updated review of the evidence. Psychophysiology 2017. [CrossRef] [PubMed]

14. Ley, R.G.; Bryden, M.P. Hemispheric differences in processing emotions and faces. Brain Lang. 1979, 7, 127-138. [CrossRef]

15. Grimshaw, G.M.; Séguin, J.A.; Godfrey, H.K. Once more with feeling: The effects of emotional prosody on hemispheric specialisation for linguistic processing. J. Neurol. 2009, 22, 313-326. [CrossRef]

16. Buchanan, T.W.; Lutz, K.; Mirzazade, S.; Specht, K.; Shah, N.J.; Zilles, K.; Jäncke, L. Recognition of emotional prosody and verbal components of spoken language: An fMRI study. Brain Res. Cogn. Brain Res. 2000, 9 , 227-238. [CrossRef]

17. Herrington, J.D.; Heller, W.; Mohanty, A.; Engels, A.S.; Banich, M.T.; Webb, A.G.; Miller, G.A. Localization of asymmetric brain function in emotion and depression. Psychophysiology 2010, 47, 442-454. [CrossRef] [PubMed]

18. Borod, J.C.; Kent, J.; Koff, E.; Martin, C.; Alpert, M. Facial asymmetry while posing positive and negative emotions: Support for the right hemisphere hypothesis. Neuropsychologia 1988, 26, 759-764. [CrossRef]

19. Canli, T.; Desmond, J.E.; Zhao, Z.; Glover, G.; Gabrieli, J.D. Hemispheric asymmetry for emotional stimuli detected with fMRI. Neuroreport 1998, 9, 3233-3239. [CrossRef] [PubMed] 
20. Davidson, R.J.; Ekman, P.; Saron, C.D.; Senulis, J.A.; Friesen, W.V. Approach-withdrawal and cerebral asymmetry: Emotional expression and brain physiology. I. J. Pers. Soc. Psychol. 1990, 58, 330-341. [CrossRef] [PubMed]

21. Silberman, E.K.; Weingartner, H. Hemispheric lateralization of functions related to emotion. Brain Cogn. 1986, 5, 322-353. [CrossRef]

22. Rodway, P.; Schepman, A. Valence specific laterality effects in prosody: Expectancy account and the effects of morphed prosody and stimulus lead. Brain Cogn. 2007, 63, 31-41. [CrossRef] [PubMed]

23. Schepman, A.; Rodway, P.; Geddes, P. Valence-specific laterality effects in vocal emotion: Interactions with stimulus type, blocking and sex. Brain Cogn. 2012, 79, 129-137. [CrossRef] [PubMed]

24. Killgore, W.D.S.; Yurgelun-Todd, D.A. The right-hemisphere and valence hypotheses: Could they both be right (and sometimes left)? Soc. Cogn. Affect. Neurosci. 2007, 2, 240-250. [CrossRef] [PubMed]

25. Heller, W. Neuropsychological mechanisms of individual differences in emotion, personality, and arousal. Neuropsychology 1993, 7, 476-489. [CrossRef]

26. Heller, W.; Nitschke, J.B.; Miller, G.A. Lateralization in emotion and emotional disorders. Curr. Dir. Psychol. Sci. 1998, 7, 26-32. [CrossRef]

27. Harmon-Jones, E.; Gable, P.A.; Peterson, C.K. The role of asymmetric frontal cortical activity in emotion-related phenomena: A review and update. Biol. Psychol. 2010, 84, 451-462. [CrossRef] [PubMed]

28. Grimshaw, G.M.; Carmel, D. An asymmetric inhibition model of hemispheric differences in emotional processing. Front. Psychol. 2014, 5, 489. [CrossRef] [PubMed]

29. Kane, M.J.; Engle, R.W. The role of prefrontal cortex in working-memory capacity, executive attention, and general fluid intelligence: An individual-differences perspective. Psychon. Bull. Rev. 2002, 9, 637-671. [CrossRef] [PubMed]

30. Falkenstein, M. Inhibition, conflict and the Nogo-N2. Clin. Neurophysiol. 2006, 117, 1638-1640. [CrossRef] [PubMed]

31. Garavan, H.; Ross, T.J.; Murphy, K.; Roche, R.A.P.; Stein, E.A. Dissociable executive functions in the dynamic control of behavior: Inhibition, error detection, and correction. NeuroImage 2002, 17, 1820-1829. [CrossRef] [PubMed]

32. Falkenstein, M.; Hoormann, J.; Hohnsbein, J. ERP components in Go/Nogo tasks and their relation to inhibition. Acta Psychol. 1999, 101, 267-291. [CrossRef]

33. Bokura, H.; Yamaguchi, S.; Kobayashi, S. Electrophysiological correlates for response inhibition in a Go/NoGo task. Clin. Neurophysiol. 2001, 112, 2224-2232. [CrossRef]

34. Nieuwenhuis, S.; Yeung, N.; van den Wildenberg, W.; Ridderinkhof, K.R. Electrophysiological correlates of anterior cingulate function in a go/no-go task: Effects of response conflict and trial type frequency. Cogn. Affect. Behav. Neurosci. 2003, 3, 17-26. [CrossRef] [PubMed]

35. Band, G.P.; van Boxtel, G.J. Inhibitory motor control in stop paradigms: Review and reinterpretation of neural mechanisms. Acta Psychol. 1999, 101, 179-211. [CrossRef]

36. Beste, C.; Saft, C.; Andrich, J.; Gold, R.; Falkenstein, M. Response inhibition in Huntington's disease-a study using ERPs and sLORETA. Neuropsychologia 2008, 46, 1290-1297. [CrossRef] [PubMed]

37. Beste, C.; Dziobek, I.; Hielscher, H.; Willemssen, R.; Falkenstein, M. Effects of stimulus-response compatibility on inhibitory processes in Parkinson's disease. Eur. J. Neurosci. 2009, 29, 855-860. [CrossRef] [PubMed]

38. Roche, R.A.P.; Garavan, H.; Foxe, J.J.; O’Mara, S.M. Individual differences discriminate event-related potentials but not performance during response inhibition. Exp.Brain Res. 2005, 160, 60-70. [CrossRef] [PubMed]

39. Liu, L.; Ioannides, A.A. Emotion separation is completed early and it depends on visual field presentation. PloS ONE 2010, 5, e9790. [CrossRef] [PubMed]

40. Rigoulot, S.; D’Hondt, F.; Honoré, J.; Sequeira, H. Implicit emotional processing in peripheral vision: Behavioral and neural evidence. Neuropsychologia 2012, 50, 2887-2896. [CrossRef] [PubMed]

41. Rigoulot, S.; Delplanque, S.; Despretz, P.; Defoort-Dhellemmes, S.; Honoré, J.; Sequeira, H. Peripherally presented emotional scenes: A spatiotemporal analysis of early ERP responses. Brain Topogr. 2008, 20, 216-223. [CrossRef] [PubMed]

42. Ocklenburg, S. Tachistoscopic viewing and dichotic listening. In Lateralized Brain Functions: Methods in Human and Non-human Species; Rogers, L.J., Vallortigara, G., Eds.; Humana Press; Springer: New York, NY, USA, 2017; Volume 122. 
43. Lang, P.J.; Bradley, M.M.; Cuthbert, B.N. Motivated attention: Affect, activation, and action. In Attention and Orienting: Sensory and Motivational Processes; Lang, P.J., Simons, R.F., Balaban, M., Eds.; Lawrence Erlbaum Associates: Mahwah, NJ, USA, 1997; pp. 97-135.

44. Albert, J.; López-Martín, S.; Carretié, L. Emotional context modulates response inhibition: Neural and behavioral data. NeuroImage 2010, 49, 914-921. [CrossRef] [PubMed]

45. Albert, J.; López-Martín, S.; Tapia, M.; Montoya, D.; Carretié, L. The role of the anterior cingulate cortex in emotional response inhibition. Hum. Brain Mapp. 2012, 33, 2147-2160. [CrossRef] [PubMed]

46. Buodo, G.; Sarlo, M.; Mento, G.; Messerotti Benvenuti, S.; Palomba, D. Unpleasant stimuli differentially modulate inhibitory processes in an emotional Go/NoGo task: An event-related potential study. Cogn. Emot. 2017, 31, 127-138. [CrossRef] [PubMed]

47. Chiu, P.H.; Holmes, A.J.; Pizzagalli, D.A. Dissociable recruitment of rostral anterior cingulate and inferior frontal cortex in emotional response inhibition. NeuroImage 2008, 42, 988-997. [CrossRef] [PubMed]

48. López-Martín, S.; Albert, J.; Fernández-Jaén, A.; Carretié, L. Emotional response inhibition in children with attention-deficit/hyperactivity disorder: Neural and behavioural data. Psychol. Med. 2015, 45, 2057-2071. [CrossRef] [PubMed]

49. Yu, F.; Yuan, J.; Luo, Y.-J. Auditory-induced emotion modulates processes of response inhibition: An event-related potential study. Neuroreport 2009, 20, 25-30. [CrossRef] [PubMed]

50. De Houwer, J.; Tibboel, H. Stop what you are not doing! Emotional pictures interfere with the task not to respond. Psychon. Bull. Rev. 2010, 17, 699-703. [CrossRef] [PubMed]

51. Zhang, W.; Lu, J. Time course of automatic emotion regulation during a facial Go/Nogo task. Biol. Psychol. 2012, 89, 444-449. [CrossRef] [PubMed]

52. Grimshaw, G.M.; Kranz, L.S.; Carmel, D.; Moody, R.E.; Devue, C. Contrasting reactive and proactive control of emotional distraction. Emotion 2017. [CrossRef] [PubMed]

53. Calvo, M.G.; Avero, P. Affective priming of emotional pictures in parafoveal vision: Left visual field advantage. Cogn. Affect. Behav Neurosci 2008, 8, 41-53. [CrossRef] [PubMed]

54. Ocklenburg, S.; Güntürkün, O.; Beste, C. Lateralized neural mechanisms underlying the modulation of response inhibition processes. NeuroImage 2011, 55, 1771-1778. [CrossRef] [PubMed]

55. Oldfield, R.C. The assessment and analysis of handedness: The Edinburgh inventory. Neuropsychologia 1971, 9, 97-113. [CrossRef]

56. Wascher, E.; Wauschkuhn, B. The interaction of stimulus- and response-related processes measured by event-related lateralizations of the EEG. Electroencephalogr. Clin. Neurophysiol. 1996, 99, 149-162. [CrossRef]

57. Miller, J. Contralateral and ipsilateral motor activation in visual simple reaction time: A test of the hemispheric coactivation model. Exp. Brain Res. 2007, 176, 539-558. [CrossRef] [PubMed]

58. Perrin, F.; Pernier, J.; Bertrand, O.; Echallier, J.F. Spherical splines for scalp potential and current density mapping. Electroencephalogr. Clin. Neurophysiol. 1989, 72, 184-187. [CrossRef]

59. D'Alberto, N.; Funnell, M.; Potter, A.; Garavan, H. A split-brain case study on the hemispheric lateralization of inhibitory control. Neuropsychologia 2017, 99, 24-29. [CrossRef] [PubMed]

60. Aron, A.R.; Robbins, T.W.; Poldrack, R.A. Inhibition and the right inferior frontal cortex. Trends Cogn. Sci. 2004, 8, 170-177. [CrossRef] [PubMed]

61. Aron, A.R.; Robbins, T.W.; Poldrack, R.A. Inhibition and the right inferior frontal cortex: One decade on. Trends Cogn. Sci. 2014, 18, 177-185. [CrossRef] [PubMed]

62. Ocklenburg, S.; Ness, V.; Güntürkün, O.; Suchan, B.; Beste, C. Response inhibition is modulated by functional cerebral asymmetries for facial expression perception. Front. Psychol. 2013, 4, 879. [CrossRef] [PubMed]

63. Livesey, E.J.; Livesey, D.J. Validation of a Bayesian Adaptive Estimation Technique in the Stop-Signal Task. PLoS ONE 2016, 11, e0165525. [CrossRef] [PubMed]

64. Verbruggen, F.; McLaren, R. Effects of reward and punishment on the interaction between going and stopping in a selective stop-change task. Psychol. Res. 2016. [CrossRef] [PubMed]

65. Lange, F.; Seer, C.; Müller, D.; Kopp, B. Cognitive caching promotes flexibility in task switching: Evidence from event-related potentials. Sci. Rep. 2015, 5, 17502. [CrossRef] [PubMed]

(C) 2017 by the authors. Licensee MDPI, Basel, Switzerland. This article is an open access article distributed under the terms and conditions of the Creative Commons Attribution (CC BY) license (http:/ / creativecommons.org/licenses/by/4.0/). 